\section{The Availability of Information on Impaired Renal Function in the Community Pharmacy, A Descriptive Pilot Study}

\section{Smits $E^{1 *}$, Houben $E^{1}$, de Smet PAGM ${ }^{3,4}$, Szerencsi $K^{1}$, van Herk-Sukel MPP ${ }^{1}$, Herings RMC ${ }^{1}$ and Teichert $\mathrm{M}^{2,3}$}

${ }^{1}$ PHARMO Institute for Drug Outcomes Research, Utrecht, The Netherlands

${ }^{2}$ Department of IQ Healthcare, Radboud University Medical Centre, Radboud Institute for Health Sciences, Nijmegen, The Netherlands

${ }^{3}$ Royal Dutch Pharmacists Association, The Hague, The Netherlands

${ }^{4}$ Departments of Clinical Pharmacy and IQ Healthcare, Radboud University Medical Centre, Radboud Institute for Health Sciences, Nijmegen, The Netherlands

\begin{abstract}
Aim

Renal function is associated with medication errors and related severe adverse events. The study's objective was to explore the availability of renal function tests in Dutch community pharmacies to be used for medication safety surveillance in accordance with data sharing regulations of clinical laboratory tests as of August 1, 2013. Methods

A retrospective cross sectional descriptive study was performed using data from the PHARMO Database Network (including general practitioner, community pharmacy and clinical laboratory data). Patients with an impaired renal function ( $<60 \mathrm{MDRD} \mathrm{ml} / \mathrm{min} / 1.73 \mathrm{~m} 2$ ) without the use of risk medication, or patients with an impaired renal function ( $<50 \mathrm{MDRD} \mathrm{ml} / \mathrm{min} / 1.73 \mathrm{~m} 2)$ with the use of risk medication were selected from five community pharmacies included in the PHARMO Database Network and data collection on site (in the community pharmacy) was performed to determine the available information at the pharmacy.

\section{Results}

549 patients with a reduced kidney function were included in this study of which 273 without risk medication and 276 with risk medication. For $37 \%$ of patients with available information on impaired renal function in the PHARMO Database Network, this
\end{abstract}

*Corresponding author: Smits E, PHARMO Institute for Drug Outcomes Research, van Deventerlaan 30-40 3528 AE Utrecht, The Netherlands, Tel: +31 307440824; E-mail: lisa.smits@pharmo.nl

Citation: Smits E, Houben E, de Smet PAGM, Szerencsi K, van Herk-Sukel MPP, et al. (2016) The Availability of Information on Impaired Renal Function in The Community Pharmacy, A Descriptive Pilot Study. J Nephrol Renal Ther 2: 003.

Received: January 05, 2016; Accepted: February 22, 2016; Published: March 08, 2016 information was also available in community pharmacies. This was $52 \%$ for patients using risk medication with an impaired renal function. Percentages in the presence of available information varied from $16 \%$ to $77 \%$ between pharmacies.

\section{Conclusion}

The presence of available information on renal function in community pharmacies was insufficient for patients with renal impairment. This hinders effective medication surveillance. The variation in information present in the pharmacies might depend on the willingness of patients to share laboratory measures with their community pharmacists as well as the willingness of prescribers and laboratories to share the information. Future research should examine which factors are independently associated with the presence of available information and should be used for interventions focusing on improving information exchange with the community pharmacy.

Keywords: Descriptive pilot study; Impaired renal function; MDRD

\section{Introduction}

Unintended and adverse drug effects due to medication errors are a major source of potentially avoidable hospitalisations. Several studies performed the past 20 years estimated a range in the percentage of hospital admissions between 3 and $10 \%$ of which $50 \%$ were potentially avoidable [1]. In The Netherlands, about $5 \%$ of all unplanned hospital admissions have been associated with suboptimal drug use of which $40-46 \%$ was potentially preventable [2]. Other Dutch studies reported annually 41.000 medication related hospital admissions of which 16.000 admissions were potentially preventable [3]. From the patients with potentially preventable admissions nearly $7 \%$ died due to medication errors $[2,4,5]$. Knowledge about factors associated with medication errors and related severe adverse events offers targets for prevention. One of these factors is impaired renal function, because it alters the excretion of renally cleared drugs and their metabolites, which can lead to modifications in their distribution, transport and biotransformation, hence while chronic renal failure can also affect the pharmacodynamics of certain drugs [6]. To avoid excessive accumulation of drugs and active drug metabolites in patients with impaired kidney function, dosage changes or therapeutics alternatives are necessary [6,7]. A recent study showed that impaired renal function was most likely associated with $10 \%$ of the potentially preventable hospital admissions [8].

To improve drug safety in patients with impaired renal function expert knowledge and triage commonly use employed by community and hospital pharmacists is required. Actual information on the renal function and drug use has to be available at drug prescribing and dispensing. In The Netherlands community pharmacists have insight in the actual patient medication and have an important function in medication surveillance [9]. Most Dutch patients visit one community pharmacy [10]. Until 2011, automated medication surveillance in community pharmacies was based on information on drugs in current use only as information on laboratory parameters of diagnosis was not routinely available. A recent study conducted in The Netherlands showed that medication errors were detected in $15 \%$ of the patients with a eGFR $<40 \mathrm{ml} / \mathrm{min} / 1.73 \mathrm{~m} 2$ and that the majority of the errors 
required medication adjustments as recommended by the pharmacist [11]. Other studies have reported similar statistics regarding inappropriate prescribing in a population with renal impairment $[12,13]$. To improve medication surveillance in order to avoid hospitalisations due to unintended drug effects caused by renal impairment, Dutch law was altered in 2011, making the sharing of information on kidney function between general practitioners and pharmacist obligatory. Dutch pharmacists were permitted by law to request the results from laboratory measurements, including kidney function for patients to whom they dispense medication. Prescribers were then obliged to provide pharmacists with the requested information [14]. In 2013, the law was further adapted. Since then, health care professionals (medical specialists and general practitioners) have to actively inform pharmacists on laboratory measurements from their patients with an impaired renal function [15]. In addition, the community pharmacist may continue to ask information on kidney function from a prescriber when this is deemed relevant for drug dispensing. Despite these new legislation however, there is no systematic disposition to provide community pharmacists with this essential information in a systematic way. Furthermore, the pharmacist depends on other professionals to receive this information. At this moment it is unknown to what extent community pharmacists have information that is actually available on reduced kidney function of their patients at their disposal.

The main objective of this descriptive study is to explore the availability of renal function tests in Dutch community pharmacies to be used for medication safety surveillance in accord with data sharing regulations of clinical laboratory tests as of August 1, 2013.

\section{Methods}

\section{The PHARMO database network}

A retrospective cross sectional descriptive study was conducted using data from the PHARMO Database Network. The PHARMO Database Network is a dynamic population based network including multiple patient centric observational databases. Databases relevant for this study are: the Clinical Laboratory Database Community (outpatient) Pharmacy Database and the General Practitioners Database. These databases are linked on a patient level through validated algorithms [16].

\section{Measure of information availability}

Data on laboratory assessments of renal function were obtained from the Clinical Laboratory Database and the General Practitioner Database of the PHARMO Database Network. This data was used as golden standard.

\section{Selection of patients}

All patients who were registered in the designated, geodemographic catchment area of five community pharmacies (population size $\sim 50.000$, which were chosen based on the overlap between their patient population and the population with information available in the Clinical Laboratory Database and General Practitioner Database) and were available in the PHARMO Database Network were selected. Data concerning renal function tests (creatinine and MDRD) of these patients were extracted from the designated pharmacies themselves (I), general practitioners (II) and clinical laboratories (III).

Furthermore, patients had to meet the following criteria: [1] Patients were between 20 and 95 years of age, [2] patients needed to have at least one renal function test (MDRD measurement) recorded in either in the Clinical Laboratory Database or in the General Practitioner Database between January $1^{\text {st }} 2013$ and July $1^{\text {st }} 2014$.

Of these patients, two groups of patients were selected [1]. Patients with an impaired renal function $(<60 \mathrm{MDRD} \mathrm{ml} / \mathrm{min} / 1.73 \mathrm{~m} 2)$ and without a dispensed drug that could impair renal function or that was contraindicated for use in patients with impaired renal function ('risk medication') [2]. Patients with an impaired renal function $(<50$ MDRD $\mathrm{ml} / \mathrm{min} / 1.73 \mathrm{~m} 2$ ) and with 'risk medication'. A list of drugs contraindicated in impaired renal function ('risk medication') was available from the Dutch Association for the Advancement [17].

For impaired renal function two threshold values were used, as threshold values for impaired renal function vary between guidelines. A MDRD $<60 \mathrm{ml} / \mathrm{min} / 1.73 \mathrm{~m} 2$ is used as threshold value for impaired renal function in various guidelines focusing on detection and treatment of impaired renal function [18-20]. A MDRD $<50 \mathrm{ml} / \mathrm{min} / 1.73 \mathrm{~m} 2$ is used as threshold value for impaired renal function in relation to required medication adjustments [17,21]. In the Dutch legislation of July 2013, in which the exchange of information on lab values regarding impaired renal function is regulated, impaired kidney function is defined as a MDRD $<50 \mathrm{ml} /$ $\min / 1.73 \mathrm{~m} 2$ [15]. However, in the legislation of 2011 no specific threshold values were mentioned. As the information availability was assessed for the period January 2013 up to July 2014, it is uncertain which threshold value $(<60$ of $<50)$ for impaired renal function was used by the health care providers (during the period January 2013-July 2013). Therefore a MDRD $<60 \mathrm{ml} / \mathrm{min} / 1.73 \mathrm{~m} 2$ was used for a subgroup of patients without risk medication, to meet both guidelines. A MDRD $<50 \mathrm{ml} / \mathrm{min} / 1.73 \mathrm{~m} 2$ was used for a subgroup of patients with risk medication, because this threshold value is more in line with the guideline which is in relation with medication adjustments.

The patients were grouped per sample pharmacy. From each subgroup a random sample of up to 70 patients was drawn, resulting in a maximum of 140 patients per pharmacy to restrict the work load associated with the data collection on site (in the community pharmacy). If less than 70 patients were available, no random sample was drawn (Figure 1).

\begin{tabular}{|c|c|c|}
\hline $\begin{array}{l}\text { Selection of } \\
\text { patients from } \\
\text { pharmacies } \\
\text { participating in the } \\
\text { PHARMO }\end{array}$ & \multicolumn{2}{|c|}{$\begin{array}{l}\text { Patients (aged 20-95) with a MDRD measurement recorded between } \\
\text { January } 1^{*} 2013 \text { and July } 1^{\text {" }} 2014 \text { (as recorded in the laboratory DB* or in } \\
\text { the GP DB**) and registered in one of the five pharmacies } \\
\qquad \mathrm{N}=10.367\end{array}$} \\
\hline & $\downarrow$ & $\downarrow$ \\
\hline $\begin{array}{l}\text { Selection of patients } \\
\text { with an impaired renal } \\
\text { function with/without } \\
\text { risk medication use }\end{array}$ & $\begin{array}{c}\text { Patients with impaired } \\
\text { renal function }(\mathrm{MDRD}< \\
50 \mathrm{ml} / \mathrm{min} / 1.73 \mathrm{~m} 2) \text { and use } \\
\text { of risk medication } \\
\mathrm{N}=852\end{array}$ & $\begin{array}{c}\text { Patients with impaired } \\
\text { renal function }(\text { MDRD }< \\
60 \mathrm{ml} / \mathrm{min} / 1.73 \mathrm{~m} 2) \\
\text { without use of risk } \\
\text { medication }\end{array}$ \\
\hline \multirow[b]{2}{*}{$\begin{array}{l}\text { Sample used to assess the } \\
\text { information availability } \\
\text { onimpaired renal function } \\
\text { in the community } \\
\text { pharmacy (= denominator) }\end{array}$} & $\downarrow$ & $\downarrow$ \\
\hline & $\begin{array}{l}\text { Per phamacy a } \\
\text { random sample of } \\
\text { up to } 70 \text { patients } \\
\text { was included. } \\
\quad \mathrm{N}=276\end{array}$ & $\begin{array}{l}\text { Per pharmacy a } \\
\text { random sample of } \\
\text { up to } 70 \text { patients } \\
\text { was included. } \\
\quad \mathrm{N}=273\end{array}$ \\
\hline \multicolumn{3}{|c|}{ Figure 1: Patient selection. } \\
\hline \multicolumn{3}{|c|}{ *Laboratory DB=Clinical Laboratory Database } \\
\hline \multicolumn{3}{|c|}{${ }^{* *}$ GP DB $=$ General Practitioners Database } \\
\hline
\end{tabular}

\section{Definitions}

The use of risk medication in patients with impaired renal function was defined as the use of drugs, within the year after a MDRD test with a value below $50 \mathrm{ml} / \mathrm{min} / 1.73 \mathrm{~m} 2$, which 1 ) requiring special attention 
Citation: Smits E, Houben E, de Smet PAGM, Szerencsi K, van Herk-Sukel MPP, et al. (2016) The Availability of Information on Impaired Renal Function in The Community Pharmacy, A Descriptive Pilot Study. J Nephrol Renal Ther 2: 003.

- Page 3 of 7 •

\begin{tabular}{|c|c|c|c|c|c|}
\hline & Pharmacy I & Pharmacy II & Pharmacy III & Pharmacy IV & Pharmacy V \\
\hline \multicolumn{6}{|l|}{ Pharmacy characteristics } \\
\hline $\begin{array}{l}\text { Number of patients in the } \\
\text { pharmacy* }\end{array}$ & 10,004 & 5,021 & 9,704 & 8,850 & 4,153 \\
\hline $\begin{array}{l}\text { Located in a health care } \\
\text { centre }\end{array}$ & No & Yes & Yes & No & No \\
\hline $\begin{array}{l}\text { Population size of city in } \\
\text { which the pharmacy is } \\
\text { located }\end{array}$ & 12,815 & 217,895 & 88,800 & 141,895 & 141,895 \\
\hline $\begin{array}{c}\text { Description of information } \\
\text { system with regard to lab } \\
\text { values }\end{array}$ & $\begin{array}{c}\text { If GP and pharmacist } \\
\text { share the same informa- } \\
\text { tion system, requested lab } \\
\text { tests can be automatically } \\
\text { transferred from the GP's } \\
\text { system to the pharmacist } \\
\text { system }\end{array}$ & $\begin{array}{l}\text { If GP and pharmacist } \\
\text { share the same informa- } \\
\text { tion system, requested lab } \\
\text { tests can be automatically } \\
\text { transferred from the GP's } \\
\text { system to the pharmacist } \\
\text { system }\end{array}$ & $\begin{array}{l}\text { If GP and pharmacist } \\
\text { share the same informa- } \\
\text { tion system, the patients' } \\
\text { medical record, including } \\
\text { lab values, kept by the GP } \\
\text { can be viewed }\end{array}$ & $\begin{array}{l}\text { Lab values are entered } \\
\text { manually in the patients } \\
\text { file }\end{array}$ & $\begin{array}{c}\text { If GP and pharmacist } \\
\text { share the same informa- } \\
\text { tion system, the patients' } \\
\text { medical record, including } \\
\text { lab values, kept by the GP } \\
\text { can be viewed }\end{array}$ \\
\hline Collaboration forms & GP's & GP's & $\begin{array}{c}\text { GP's and hospital lab- } \\
\text { oratory }\end{array}$ & GP's & GP's \\
\hline
\end{tabular}

Patient characteristics of the population in the sample registered in the PHARMO Database Network, used to assess the availability of information on renal function in the community pharmacy

\begin{tabular}{|c|c|c|c|c|c|}
\hline Total size of sample & 139 & 97 & 134 & 140 & 39 \\
\hline $\begin{array}{l}\text { Use of risk medication No } \\
\text { risk medication (MDRD< } \\
60 \mathrm{ml} / \mathrm{min} / 1.73 \mathrm{~m} 2)\end{array}$ & 71 & 44 & 73 & 69 & 16 \\
\hline $\begin{array}{l}\text { Risk medication (MDRD< } \\
50 \mathrm{ml} / \mathrm{min} / 1.73 \mathrm{~m} 2)\end{array}$ & 68 & 53 & 61 & 71 & 23 \\
\hline \multicolumn{6}{|l|}{ Sex } \\
\hline Male & $63(45 \%)$ & $49(50 \%)$ & $63(49 \%)$ & $44(31 \%)$ & $7(18 \%)$ \\
\hline Female & 76 (55\%) & $48(50 \%)$ & $71(51 \%)$ & $96(69 \%)$ & $32(82 \%)$ \\
\hline \multicolumn{6}{|l|}{ Age } \\
\hline $20-70$ & $45(33 \%)$ & $32(33 \%)$ & $51(38 \%)$ & $55(39 \%)$ & $4(10 \%)$ \\
\hline $71-95$ & $94(67 \%)$ & $65(67 \%)$ & $83(62 \%)$ & $85(61 \%)$ & $35(90 \%)$ \\
\hline \multicolumn{6}{|l|}{ CVD } \\
\hline Yes & $25(18 \%)$ & $9(9 \%)$ & $36(27 \%)$ & $35(25 \%)$ & $15(38 \%)$ \\
\hline \multicolumn{6}{|l|}{ Hypertension } \\
\hline Yes & $21(15 \%)$ & $14(14 \%)$ & $22(16 \%)$ & $42(30 \%)$ & $14(36 \%)$ \\
\hline No & $118(85 \%)$ & $83(86 \%)$ & $112(84 \%$ & $98(70 \%)$ & $25(64 \%)$ \\
\hline \multicolumn{6}{|l|}{ Diabetes } \\
\hline Yes & $9(7 \%)$ & $7(7 \%)$ & $18(13 \%)$ & $22(16 \%)$ & $6(15 \%)$ \\
\hline No & $130(93 \%)$ & $90(93 \%)$ & $116(87 \%)$ & $118(84 \%)$ & $33(85 \%)$ \\
\hline
\end{tabular}

Table 1: Characteristics of the five participating community pharmacies and patient characteristics within the random sample per community pharmacy. *assessed in December 2014

$\mathrm{GP}=$ General Practitioner

$C V D=$ Cardiovascular Disease

in renal impairment, 2) have special features in renal impairment,

3) have controversies surrounding their use in renal impairment,

4) have new insights concerning their use in renal impairment or

5) have narrow therapeutic window [21] (Appendix 1, Table 1). Medication use was extracted from the Pharmacy Database.

Patient at risk for renal impairment were defined as patients of 70 years or older, with a diagnosis of diabetes (ICPC code: T90.02 for diabetes mellitus type II), hypertension (ICPC code: K86.00) or cardiovascular disease (CVD: ICPC codes: K74.00, K75.00, K76.00, K77.00, K89.00, K90.00, K90.02, K90.03, K92.00 and K99.0) [22]. Renal function had to be assessed at/or before the index date, which was defined as the date of the first kidney function measurement in the study period.

\section{Analyses}

The presence of available information on impaired renal function in the community pharmacies was calculated and presented in frequency distributions. Furthermore, the overall information availability per pharmacy was determined. Finally, per pharmacy the presence of available information was calculated a) among patients with and b) without selected risk medication and in patients according to age, gender and co-morbidities. The percentage of patients with available information on impaired renal function in the community pharmacy was calculated as: the number of patients with a known MDRD value in the community pharmacy (numerator) relative to the total number of patients with a registered MDRD value in the PHARMO General Practitioner Database or Clinical 
Laboratory Database (denominator), which was used as golden standard.

\section{Results}

In total 549 patients with a reduced kidney function were included in this study of which 273 without risk medication and 276 with risk medication. Of these, 139 were included for Pharmacy I, and 140 for Pharmacy IV (maximum number of 140 patients could be included per pharmacy). In the other pharmacies less than 140 patients were available. From the originally selected 138 patients in pharmacy III, 4 patients could not be retraced in the PHARMO Database Network because their personal unique identifier number had been reassigned. In $4 \%$ of the patients $(\mathrm{N}=24)$ risk medication use status was reclassified, leading to a small deviation from the original number of patients with and without risk medication use.

Table 1 describes the characteristics of the study population and the pharmacies. Sex was evenly distributed in the random samples of pharmacies I-III, whereas in the random samples of pharmacies IV and V $69 \%$ and $82 \%$ of the population was female. In pharmacies I to IV about $60 \%$ of the patients included in the random sample was 70 years or older, whereas in pharmacy $\mathrm{V}$ this was $90 \%$. Furthermore, differences were observed in the percentage of patients with CVD, hypertension and diabetes in the random samples of the different pharmacies.

In table 2, the results regarding the presence of available information on renal function in the community pharmacy are presented per subgroups (according to risk medication use) and stratified by patient characteristics. The number of patients with available information on impaired renal function in the community pharmacy (numerator) is presented relative to the number of patients with information available on impaired renal function as registered in the PHARMO Database Network (denominator), the percentage of patients using risk medication with a present information on reduced renal function ranged from $25 \%$ to $74 \%$ per pharmacy. In patients older than 70 years the percentage of present information was higher than in younger patients (20-70 years old). In patients with Comorbidities (CVD, hypertension or diabetes) the percentage of present information was higher than in patients without comorbidities.

The average presence of available information on impaired renal function in all 5 subsamples pooled together was 37\%. The average information presence in patients with risk medication was $52 \%$. The percentage of present information was higher in older than in younger patients ( $43 \%$ vs $25 \%$ ), in patients with than without CVD (63\% vs $30 \%$ ), with and without hypertension ( $44 \%$ vs $35 \%$ ) and with than without diabetes ( $56 \%$ vs $35 \%$ ).

\section{Discussion}

The main finding of this study was that presence of available information on impaired renal function in community pharmacies was far from complete. On average, information on impaired renal function was available in the community pharmacies for $37 \%$ of the study population.

The percentages of the presence of available information on impaired renal function varied between the pharmacies from $16 \%$ to $77 \%$. This variation might be due to differences in the extent and forms of collaboration of the pharmacists with GPs and/or clinical laboratories as reported by the participating pharmacists, e.g., the information system used (including the technical possibilities to exchange information on kidney function between GP's and pharmacists). Furthermore the variation in information on renal impairment present in the pharmacies might depend on the willingness of patients to share laboratory measures with their community pharmacists as well as the willingness of prescribers and laboratories to share the information.

Some awareness to share this information for risk patients or users of risk medication was noted as the percentage of present information on renal function was higher for these patients (52\%). Differences were observed in the information availability according to patient characteristics. In our study we found that the percentage of available information on impaired renal function was higher in patients of old age and in patients with selected Comorbidities (CVD, hypertension and diabetes). Patients of old age, with CVD, hypertension and diabetes are considered at increased risk of reduced renal function. GP's are advised in their guidelines to detect renal impairment in these patients at an early stage [18-20]. Based on this information dosages or therapy regimen can be adapted to individual patient's needs. The increased awareness to detect patients with renal impairment and the re-evaluation of the medication regimen in these patients might be an explanation for the higher availability of information on impaired renal function in the community pharmacy for these patients. However, even for those patients information on renal function to perform proper medication surveillance was insufficiently complete.

Besides, other quality aspects of the information as the completeness, actuality and the correctness with the values measured are crucial for proper medication surveillance. When taking these parameters also into account, the percentage of information availability in community pharmacies might be even lower.

Finally, the patient's consent, which is required for exchange of information about the kidney function, could be a limitation factor [23]. This may hinder the information exchange.

However, it can be concluded that the implementation of the legal obligation to share this knowledge with community pharmacists should be improved. The availability of information on impaired renal function in the community pharmacies is important as this precondition for pharmacists to perform medication surveillance.

\section{Strengths and Limitations}

In this study, we only traced information on the presence of available information on renal function in a subset of five community pharmacies located in the PHARMO Database Network. These pharmacies were chosen based on the overlap between their patient population and the population with information available in the Clinical Laboratory Database and the General Practitioner Database. Possibly pharmacies in areas for which the PHARMO Database Network disposes over data shared from different sources the collaboration between health care providers and laboratories is already better. Thus our results may rather over-than underestimate the general situation in The Netherlands. Furthermore, the pharmacists of the selected pharmacies were willing to participate. It might be that these pharmacies were better in obtaining information on impaired kidney function.

The information availability was assessed for the period January 2013 to July 2014. It was assumed that a recorded MDRD measurement in the community pharmacy became available to the 
Citation: Smits E, Houben E, de Smet PAGM, Szerencsi K, van Herk-Sukel MPP, et al. (2016) The Availability of Information on Impaired Renal Function in The Community Pharmacy, A Descriptive Pilot Study. J Nephrol Renal Ther 2: 003.

- Page 5 of $7 \bullet$

\begin{tabular}{|c|c|c|c|c|c|c|}
\hline & Pharmacy I & Pharmacy II & Pharmacy III & Pharmacy IV & Pharmacy V & Total \\
\hline Overall & $41 / 139(30 \%)$ & $16 / 97(16 \%)$ & $48 / 134(36 \%)$ & $67 / 140(48 \%)$ & $30 / 39(77 \%)$ & $202 / 549(37 \%)$ \\
\hline $\begin{array}{l}\text { Risk medication use } \\
\text { No risk medication }\end{array}$ & $13 / 71(19 \%)$ & $3 / 44(7 \%)$ & $15 / 73(21 \%)$ & $15 / 69(22 \%)$ & $13 / 16(81 \%)$ & $59 / 273(22 \%)$ \\
\hline Risk medication & $28 / 68(41 \%)$ & $13 / 53(25 \%)$ & $33 / 61(54 \%)$ & $52 / 71(72 \%)$ & $17 / 23(74 \%)$ & $143 / 276(52 \%)$ \\
\hline \multicolumn{7}{|l|}{ Sex } \\
\hline Male & $17 / 63(27 \%)$ & $10 / 49(20 \%)$ & $23 / 63(37 \%)$ & $21 / 44(48 \%)$ & $6 / 7(86 \%)$ & $77 / 226(34 \%)$ \\
\hline Female & $24 / 76(17 \%)$ & $6 / 48(13 \%)$ & $25 / 71(35 \%)$ & $46 / 96(48 \%)$ & $24 / 32(75 \%)$ & $125 / 323(39 \%)$ \\
\hline \multicolumn{7}{|l|}{ Age } \\
\hline $20-70$ & $10 / 45(24 \%)$ & $3 / 32(9 \%)$ & $12 / 51(24 \%)$ & $19 / 55(35 \%)$ & $2 / 4(50 \%)$ & $46 / 187(25 \%)$ \\
\hline $70-95$ & $31 / 94(33 \%)$ & $13 / 65(20 \%)$ & $36 / 83(43 \%)$ & $48 / 85(56 \%)$ & $28 / 35(80 \%)$ & $156 / 362(43 \%)$ \\
\hline \multicolumn{7}{|l|}{ CVD } \\
\hline Yes & $12 / 25(48 \%)$ & $5 / 9(56 \%)$ & $23 / 36(64 \%)$ & $25 / 35(71 \%)$ & $10 / 15(67 \%)$ & $75 / 120(63 \%)$ \\
\hline \multicolumn{7}{|l|}{ Hypertension } \\
\hline Yes & $7 / 21(33 \%)$ & $4 / 14(29 \%)$ & 7/ $22(32 \%)$ & $22 / 42(52 \%)$ & $10 / 14(71 \%)$ & $50 / 113(44 \%)$ \\
\hline No & $34 / 118(29 \%)$ & $12 / 83(14 \%)$ & $41 / 112(37 \%)$ & $45 / 98(46 \%)$ & $20 / 25(80 \%)$ & $152 / 436(35 \%)$ \\
\hline \multicolumn{7}{|l|}{ Diabetes } \\
\hline Yes & $4 / 9(50 \%)$ & $3 / 7(43 \%)$ & $10 / 18(56 \%)$ & $12 / 22(54 \%)$ & $5 / 6(83 \%)$ & $34 / 62(56 \%)$ \\
\hline No & $37 / 130(28 \%)$ & $13 / 90(14 \%)$ & $38 / 116(33 \%)$ & $55 / 118(47 \%)$ & $25 / 33(76 \%)$ & $168 / 487(35 \%)$ \\
\hline
\end{tabular}

Table 2: The number of patients with available information on impaired renal function in the community pharmacy (numerator) relative to the number of patients with impaired renal function registered in the PHARMO Database Network (denominator), presented as percentages per pharmacy and as total, according to risk medication use and patient characteristics.

pharmacist around the same time as it was recorded in the clinical laboratory (and vice versa) and that the results of this study indeed assess information availability during the specified time window. However, pharmacists might have obtained information on renal function with a delay and thus after the end of our study period. This might underestimate the percentage of present information; however it is unlikely to explain the whole gap between information in the community pharmacies and the measurements on renal function available. Another limitation was that we defined risk patients based on the information on diagnoses available in the PHARMO Database Network. This might have missed patients at risk for renal impairment, whereby the subgroup of risk patients which should be additionally monitored for their renal function might have been too specific. We furthermore focused on the availability of information on renal function, defined as an available MDRD measurement. As other measures exist to estimate kidney function, the possibility exists that the focus on the MDRD could have led to an underestimation of the available information on kidney function in the pharmacy. However, we consider the risk of bias as negligible since pharmacists mentioned the MDRD as most common measure to estimate renal function and the MDRD is the recommended measure to estimate kidney function in various Dutch guidelines $[18,24]$. In addition, most laboratories report the MDRD when serum creatinine is requested. Furthermore, the list of risk medication included in our study was only a selection from all drugs that need dosage adjustment or a change in therapy. Thus some subjects might have been wrongly placed within the subgroup without risk medication. However, this misclassification is expected to be low as the risk medication included here was chosen with regard to the prescription frequency.

The strength of this study is that we offer insight into the daily practice regarding the presence of available information on impaired renal function in Dutch community pharmacies. Furthermore, data for the study were obtained from the PHARMO Database Network in The Netherlands. This population-based network combines data from different healthcare settings, including general practitioner and clinical laboratory. Data sources are linked on a patient level through validated algorithms.

\section{Implications}

The study findings indicate that for $63 \%$ of the subjects with information available on impaired renal function this information was not present in the community pharmacy. For $48 \%$ of the subjects with risk medication this information could not be used for proper medication surveillance. Medication surveillance is crucial in patients with renal impairment and especially in those using risk medication since non-compliance to dose adjustments in patients with renal impairment is common and medication errors and dosing difficulties occur frequently (Franke et al., 2000; Yap et al., 2005; Desrochers et al., 2011, Minutolo et al., 2008).

\section{Recommendations}

More efforts should be made to share information on impaired renal function between prescribers and community pharmacists. With more insight into the barriers of the implementation for this, these could be addressed directly. There might be barriers concerning the willingness of patients to share the results from their laboratory measurements with community pharmacists and concerns from prescribers to do so. Furthermore, technical support to share information between laboratory, prescribers and community pharmacies in an easy accessible way might be a barrier. The efforts required to collect the information needed already showed that information on renal function was not easily available in the health care setting.

Possibly technical barriers will be diminished by a new technical development are regional data sharing points ('Landelijk Schakel Punt') for electronically exchange of laboratory measurements 
Citation: Smits E, Houben E, de Smet PAGM, Szerencsi K, van Herk-Sukel MPP, et al. (2016) The Availability of Information on Impaired Renal Function in The Community Pharmacy, A Descriptive Pilot Study. J Nephrol Renal Ther 2: 003.

between laboratories, prescribers and pharmacies [25]. Other recommendations to increase the information availability are to allow pharmacists to retain the kidney tests by themselves or creating Electronic Medical Record (EMR) alerts. As an incentive, pharmacists who implement this could get remuneration.

\section{Conclusion}

Since January 1,2013, health care professionals have to actively inform pharmacists on laboratory measurements from their patients with an impaired renal function. This study shows that the presence of available information on renal function is far from complete in community pharmacies. This will hinder proper medication surveillance in risk patients.

\section{Acknowledgment}

Smits E, Houben E, de Smet PAGM, Szerencsi K, van Herk-Sukel MPP, Herings RMC and Teichert M would like to thank the community pharmacists for participating in this study in order to obtain insight in the availability of information on impaired renal function.

\section{Disclosure of Potential Conflicts of Interest}

Smits E, Houben E, Szerencsi K, van Herk-Sukel MPP and Herings RMC are employees of the PHARMO Institute of Drug Outcomes Research. This independent research institute performs financially supported studies for government and related healthcare authorities and several pharmaceutical companies.

This study was supported by an unrestricted research grant of the Royal Dutch Association on the Advancement of Pharmacy (KNMP).

\section{References}

1. Nelson KM, Talbert RL (1996) Drug-related hospital admissions. Pharmacotherapy 16: 701-707.

2. van der Hooft CS, Sturkenboom MC, van Grootheest K, Kingma HJ, Stricker $\mathrm{BH}$ (2006) Adverse drug reaction-related hospitalisations: a nationwide study in The Netherlands. Drug Saf 29: 161-168.

3. Leendertse AJ, Egberts AC, Stoker LJ, van den Bemt PM, HARM Study Group (2008) Frequency of and risk factors for preventable medication-related hospital admissions in The Netherlands. Arch Intern Med 168: 1890-1896.

4. Hartholt KA, van der Velde N, Looman CW, Panneman MJ, van Beeck EF, et al. (2010) Adverse drug reactions related hospital admissions in persons aged 60 years and over, The Netherlands, 1981-2007: less rapid increase different drugs. PLoS One 5: 13977

5. Ruiter R, Visser LE, Rodenburg EM, Trifirò G, Ziere G, et al. (2012) Adverse drug reaction-related hospitalizations in persons aged 55 years and over: a population-based study in The Netherlands. Drugs Aging 29: 225-232.

6. Verbeeck RK, Musuamba FT (2009) Pharmacokinetics and dosage adjustment in patients with renal dysfunction. Eur J Clin Pharmacol 65: 757-773.

7. Munar MY, Singh H (2007) Drug dosing adjustments in patients with chronic kidney disease. Am Fam Physician 75: 1487-1496.

8. Leendertse AJ, van Dijk EA, De Smet PA, Egberts TC, van den Bemt PM (2012) Contribution of renal impairment to potentially preventable medication-related hospital admissions. Ann Pharmacother 46: 625-633.
9. Teichert M, Griens F, Buijs E, Wensing M, De Smet PA (2014) Effectiveness of interventions by community pharmacists to reduce risk of gastrointestinal side effects in nonselective nonsteroidal anti-inflammatory drug users. Pharmacoepidemiol Drug Saf 23: 382-389.

10. Buurma H, Bouvy ML, De Smet PA, Floor-Schreudering A, Leufkens HG, et al. (2008) Prevalence and determinants of pharmacy shopping behaviour. J Clin Pharm Ther 33: 17-23.

11. Joosten H, Drion I, Boogerd KJ, van der Pijl EV, Slingerland RJ, et al. (2013) Optimising drug prescribing and dispensing in subjects at risk for drug errors due to renal impairment: improving drug safety in primary healthcare by low eGFR alerts. BMJ Open 3.

12. Desrochers JF, Lemieux JP, Morin-Bélanger C, Paradis FS, Lord A, et al. (2011) Development and validation of the PAIR (Pharmacotherapy Assessment in Chronic Renal Disease) criteria to assess medication safety and use issues in patients with CKD. Am J Kidney Dis 58: 527-535.

13. Breton G, Froissart M, Janus N, Launay-Vacher V, Berr C, et al. (2011) Inappropriate drug use and mortality in community-dwelling elderly with impaired kidney function--the Three-City population-based study. Nephrol Dial Transplant 26: 2852-2859.

14. Ministry of Health Welfare and Sports (2011) Regulation of the Minister of Health, Welfare and Sport of December 9, 2011, no. UTC / MVG-3096198, amending the Regulation on Medicines. Staatscourant, Netherlands.

15. Ministry of Health Welfare and Sports (2013) Regulation of the Minister of Health, Welfare and Sport of July 2, 2013 (attribute-125176-105466 GMT), amending the rules Medicines on the exchange of laboratory data and stating the reason for writing. Staatscourant, Netherlands.

16. Herings RMC (1993) PHARMO: a record linkage system for postmarketing surveillance of prescription drugs in the Netherlands. Pharmaco-epidemiology and - therapy, Utrecht University, Utrecht 1993: 232.

17. Royal Dutch Pharmacists Association (2013) Impaired renal function, dosing advice for drugs. Royal Dutch Pharmacists Association, Kennisbank, Netherlands.

18. De Grauw WJC, Kaasjager HAH, Bilo HJG, Faber EF, Flikweert S, et al. (2009) Landelijke Transmurale Afspraak Chronische nierschade. Huisarts en Wetenschap 52: 586-597.

19. Rutten GEHM, de Grauw WJC, Nijpels G, Houweling ST, van de Laar FA, et al. (2006) Guideline on diabetes mellitus type 2. Practitioner Act 2013 56: 512-525.

20. Dutch Society of General Practitioners (2009) Guideline on cadiovascular risk management. In: Wiersma TJ, Boukes FS, Geijer RMM, Goudswaard AN (eds.). NHG-Standaarden voor de huisarts. Utrecht, Netherlands.

21. Stevens LA, Nolin TD, Richardson MM, Feldman HI, Lewis JB, et al. (2009) Comparison of drug dosing recommendations based on measured GFR and kidney function estimating equations. Am J Kidney Dis 54: 33-42.

22. Geerts AF, De Koning FH, De Vooght KM, Egberts AC, De Smet PA, et al. (2013) Feasibility of point-of-care creatinine testing in community pharmacy to monitor drug therapy in ambulatory elderly patients. J Clin Pharm Ther 38 : 416-422.

23. Royal Dutch Pharmacists Association.

24. National Kidney Foundation (2002) K/DOQI clinical practice guidelines for chronic kidney disease: evaluation, classification, and stratification. Am J Kidney Dis 39: 1-266.

25. Pharmaceutical Weekly (2013) Exchange of lab values successfully tested. Pharmaceutical Weekly, The Hague, Netherlands. 
Citation: Smits E, Houben E, de Smet PAGM, Szerencsi K, van Herk-Sukel MPP, et al. (2016) The Availability of Information on Impaired Renal Function in The Community Pharmacy, A Descriptive Pilot Study. J Nephrol Renal Ther 2: 003.

- Page 7 of 7 •

\begin{tabular}{|c|c|}
\hline Name & ATC code \\
\hline Metformin & $\begin{array}{c}\text { A10BA02 } \\
\text { Combinations of metformin with other oral blood glucose lowering substances: } \\
\text { A10BD02, A10BD03, A10BD05, A10BD07, A10BD08, A10BD10, A10BD11, } \\
\text { A10BD13, A10BD14, A10BD15 }\end{array}$ \\
\hline Digoxin & C10AA05 \\
\hline Sotalol & C07AA07 \\
\hline Allopurinol & M04AA01 \\
\hline ACE inhibitors / All antagonists & $\begin{array}{c}\text { ACE inhibitors=C09A, C09B } \\
\text { ACE antagonists=C09C, C09D } \\
\text { except fosinopril }\end{array}$ \\
\hline Spironolactone & C03DA01 \\
\hline Levofloxacin & J01MA12 \\
\hline Tenofovir & J05AF07 \\
\hline Gabapentin & N03AX12 \\
\hline Lamivudine & J05AF05 \\
\hline Lithium & N05AN01 \\
\hline Dabigatran & B01AE07 \\
\hline Rivaroxaban & B01AX06 \\
\hline
\end{tabular}

Appendix 1: Risk medication, medication that require an action for a MDRD value $<50 \mathrm{ml} / \mathrm{min} / 1.73 \mathrm{~m} 2$ for monitoring, dose adaptation or drug cessation. 